University of Wollongong

Research Online

Faculty of Science - Papers (Archive)

Faculty of Science, Medicine and Health

$1-6-2002$

\title{
Streptococcus pyogenes prtFIl, but not sfbl, sfbll or fbp54, is represented more frequently among invasive-disease isolates of tropical Australia
}

\author{
A. Delvecchio \\ Menzies School of Health Research \\ B. J. Currie \\ Menzies School of Health Research \\ Jason D. McArthur \\ University of Wollongong, jasonm@uow.edu.au \\ Mark J. Walker \\ University of Wollongong, mwalker@uow.edu.au \\ K. S. Sriprakash \\ Queensland Institute of Medical Research
}

Follow this and additional works at: https://ro.uow.edu.au/scipapers

Part of the Life Sciences Commons, Physical Sciences and Mathematics Commons, and the Social and Behavioral Sciences Commons

\section{Recommended Citation}

Delvecchio, A.; Currie, B. J.; McArthur, Jason D.; Walker, Mark J.; and Sriprakash, K. S.: Streptococcus pyogenes prtFIl, but not sfbl, sfbll or fbp54, is represented more frequently among invasive-disease isolates of tropical Australia 2002.

https://ro.uow.edu.au/scipapers/51

Research Online is the open access institutional repository for the University of Wollongong. For further information contact the UOW Library: research-pubs@uow.edu.au 


\title{
Streptococcus pyogenes prtFII, but not sfbl, sfbll or fbp54, is represented more frequently among invasive-disease isolates of tropical Australia
}

\author{
Abstract \\ Streptococcus pyogenes (group A streptococcus) strains may express several distinct $®$ bronectinbinding \\ proteins (FBPs) which are considered as major streptococcal adhesins. Of the FBPs, Sfbl was shown in \\ Šitro to promote internalization of the bacterium into host cells and has been implicated in persistence. In \\ the tropical Northern Territory, where group A streptococcal infection is common, multiple genotypes of \\ the organism were found among isolates from invasive disease cases and no dominant strains were \\ observed. To determine whether any FBPs is associated with invasive disease propensity of S. pyogenes, \\ we have screened streptococcal isolates from bacteraemic and necrotizing fasciitis patients and isolates \\ from uncomplicated infections for genetic endowment of 4 FBPs. No difference was observed in the \\ distribution of sfbll, fbp54 and sfbl between the blood isolates and isolates from uncomplicated infection. \\ We conclude that the presence of sfbl does not appear to promote invasive diseases, despite its \\ association with persistence. We also show a higher proportion of group A streptococcus strains isolated \\ from invasive disease cases possess prtFll when compared to strains isolated from non-invasive disease \\ cases. We suggest that S. pyogenes may recruit different FBPs for different purposes.

\section{Keywords} \\ CMMB

\section{Disciplines} \\ Life Sciences | Physical Sciences and Mathematics | Social and Behavioral Sciences

\section{Publication Details} \\ This article was originally published as: Delvecchio, A, Currie, BJ, McArthur, JD, Walker, MJ \& Sriprakash, \\ KS, Streptococcus pyogenes prtFII, but not sfbl, sfbll or fbp54, is represented more frequently among \\ invasive-disease isolates of tropical Australia, Epidemiology and Infection, 2002, 128(3), 391-396. \\ Copyright 2002 Cambridge University Press. Journal information can be found here.
}




\title{
Streptococcus pyogenes prtFII, but not $s f b I$, sfbII or $f b p 54$, is represented more frequently among invasive-disease isolates of tropical Australia
}

\author{
A. DELVECCHIO ${ }^{1}$, B. J. CURRIE ${ }^{1}$, J. D. MCARTHUR ${ }^{4}$, M. J. WALKER ${ }^{4}$ \\ AND K.S. SRIPRAKASH ${ }^{1,2,3 *}$ \\ ${ }^{1}$ Menzies School of Health Research and ${ }^{2}$ Cooperative Research Centre for Aboriginal and Tropical Health, \\ Darwin, Australia \\ ${ }^{3}$ Queensland Institute of Medical Research, Brisbane, Australia \\ ${ }^{4}$ Department of Biological Sciences, University of Wollongong, NSW, Australia
}

(Accepted 18 December 2001)

\section{SUMMARY}

Streptococcus pyogenes (group A streptococcus) strains may express several distinct fibronectinbinding proteins (FBPs) which are considered as major streptococcal adhesins. Of the FBPs, $\mathrm{SfbI}$ was shown in vitro to promote internalization of the bacterium into host cells and has been implicated in persistence. In the tropical Northern Territory, where group A streptococcal infection is common, multiple genotypes of the organism were found among isolates from invasive disease cases and no dominant strains were observed. To determine whether any FBPs is associated with invasive disease propensity of $S$. pyogenes, we have screened streptococcal isolates from bacteraemic and necrotizing fasciitis patients and isolates from uncomplicated infections for genetic endowment of 4 FBPs. No difference was observed in the distribution of $s f b I I, f b p 54$ and $s f b I$ between the blood isolates and isolates from uncomplicated infection. We conclude that the presence of $s f b I$ does not appear to promote invasive diseases, despite its association with persistence. We also show a higher proportion of group A streptococcus strains isolated from invasive disease cases possess prtFII when compared to strains isolated from non-invasive disease cases. We suggest that $S$. pyogenes may recruit different FBPs for different purposes.

\section{INTRODUCTION}

Among the Aboriginal population living in the Northern Territory of Australia (NT), the incidence and prevalence of streptococcal infection and streptococcal diseases are high [1]. More than 100 different molecular types of $S$. pyogenes strains are circulating in the tropical region of the NT [2]. The incidence of acute rheumatic fever in Aboriginal populations is amongst the highest reported even though the isolation rate of $S$. pyogenes from throat swabs is low [3]. Skin is the major reservoir for $S$. pyogenes in this

* Author for correspondence: Queensland Institute of Medical Research, 300, Herston Road, Herston Qld 4006, Australia. population. The rate of streptococcal invasive diseases among the Aboriginal population is five times that of the general population and acute glomerulonephritis is endemic among the Australian Aborigines [1, 4, 5]. Interestingly, invasive $S$. pyogenes diseases in the indigenous population are not due to a dominant clone [4].

Adherence is the first step in colonization of hosts by bacterial pathogens, and bacterial adhesins may be useful vaccine antigens [6]. In S. pyogenes, adherence could be mediated by different surface exposed proteins, which include among others, fibronectin binding proteins (FBPs) [7-12]. Four FBPs (SfbI, OF, PrtFII and Fbp54) have been extensively studied. 
Among these, SfbI promotes intracellular invasion of group A streptococcus [13]. SfbI coated latex beads not only adhere to HEp2 cells but are also internalized into these cells, suggesting that SfbI by itself is sufficient for internalization of the bacteria into host cells. In some group A streptococcal strains, OF (opacity factor), a FBP responsible for causing opalescence of serum, was shown to be a major adhesin $[8,14,15]$. FBP54 was shown to be an adhesin for buccal epithelial cells but not for HEp2 cells [7]. Not all group A streptococcal strains have genetic endowment to express all the four FBPs. The differences in the repertoire of FBPs may reflect the propensity of the strains to colonize different tissues and thereby cause different patterns of diseases. To this end, a recent study [16] reported a high prevalence ( $92 \%$ ) of $s f b I$ among the persisting S. pyogenes strains from the throats of patients with asymptomatic carriage after antibiotic therapy. This observation suggests that SfbI mediated internalization may be responsible for persistence in that population. Indeed using an in vitro assay, an association between persistent isolates and a high propensity to internalise bacterial cells was demonstrated [17]. However, a more recent German study [18] did not concur with the above observation of a positive association between sfbI-positive strains and persistence. In the $\mathrm{NT}, s f b I$ is present in $60 \%$ of the $S$. pyogenes isolates [19]. Furthermore, in contrast to Connecticut [20] where throat is the primary site of infection for invasive diseases, in the NT the primary site of infection for group A streptococcus is the skin [4]. To understand the differences in epidemiology and the role of various FBPs, we have undertaken to screen group A streptococcal strains cultured from blood of patients with bacteraemia and necrotizing fasciitis, and wound and throat swabs for the genetic endowment of the four FBPs. Surprisingly, the results show that endowment for SfbI, which is the only FBP reported to mediate pathogen internalization of host cells, is not associated with invasive diseases nor is it overly represented in throat derived isolates. However, a trend showing a greater proportion of prtFIIpositivity was observed among strains recovered from the invasive disease cases.

\section{MATERIALS AND METHODS}

Strains: Group A streptococcus isolates from patients across the tropical top end of the NT between 1990-8 were characterized by a molecular typing procedure, called vir typing [21]. Vir typing is based on polymerase chain reaction (PCR) and subsequent restriction profiling of the $m g a$ locus, which comprises genes for $\mathrm{M}$ and $\mathrm{M}$-like proteins ( $\mathrm{emm}$ ), C5a peptidase $(\operatorname{scp} A)$ and a regulator $(m g a)$. The isolates were from (a) blood culture representing 35 bacteraemic and 2 necrotizing fasciitis cases (invasive diseases), and (b) 30 pyoderma and 8 throat infections. The details of the site of isolation, vir types and other characteristics are shown in Table 1. In all, 75 distinct vir types were obtained from 73 subjects. One patient had bacteraemia episodes 11 months apart with 2 distinct vir types (20.1 and 20.2) infecting, and another patient had bacteraemia with vir type 5 isolated from blood culture and 5 days later vir type 12.1 was isolated from skin. In this study, vir types 20.1, 20.2 and 5 were treated as strains from invasive disease cases and vir type 12.1 was treated as a strain from uncomplicated infection. In all, 37 vir types were from the invasive diseases and the remaining 38 were from uncomplicated infections (Table 1). In this study Aborigines account for $73 \%$ of the invasive disease cases.

DNA manipulations and Southern blots: Probes of $s f b I$ and prtFII were generated by PCR using the following primer and template combinations: for $s f b I$ : 5'-TATCAAAATCTTCTAAGTGCTGAG-3' and 5'-AATGGAACACTAACTTCGGACGGG-3' with DNA template from JRS145; and for prtFII: 5'-GAAGAAAAGCTTCCAGACGAGCAAGG-3' and 5'-GGAATCTCAGAGTTACTTTCTGGTTCC-3' with DNA template from NS1140. Composition of PCR reaction mix was according to Hartas et al. [21] and the cycling conditions were: $95^{\circ} \mathrm{C}$ for $15 \mathrm{~s}$, $50{ }^{\circ} \mathrm{C}$ (for $s f b I$ ) or $60^{\circ} \mathrm{C}$ (for prtFII) for $60 \mathrm{~s}$, and $72^{\circ} \mathrm{C}$ for $60 \mathrm{~s}$ for 30 cycles. Genomic DNA from group A streptococcus was prepared as described by Chassy [22]. Briefly, cells from overnight cultures $(5 \mathrm{ml})$ were washed in $10 \mathrm{~mm}$ Tris, $1 \mathrm{~mm}$ EDTA (TE) and resuspended in $300 \mu \mathrm{l}$ TE. To this suspension, $700 \mu 1$ of $24 \%$ polyethylene glycol 20000 in TE was added. After treatment with lysozyme $(20 \mathrm{mg} / \mathrm{ml}$, $300 \mu 1$ ), lysates were prepared by the addition of sodium dodecylsulphate (1\% in TE) and incubation at $65^{\circ} \mathrm{C}$ for $15 \mathrm{~min}$. The lysates were treated with RNase A $(10 \mathrm{mg} / \mathrm{ml})$ for $30 \mathrm{~min}$ and proteinase $\mathrm{K}$ $(20 \mathrm{mg} / \mathrm{ml})$ for $30 \mathrm{~min}$ at $37^{\circ} \mathrm{C}$. DNA was extracted by phenol/chloroform and precipitated by ethanol. The DNA pellet was dissolved in TE for further manipulations. The genomic DNA was digested with SpeI and Southern blots hybridized with the radio- 
Table 1. Characteristics of NT study isolates

\begin{tabular}{|c|c|c|c|c|c|c|c|c|c|c|c|c|c|c|c|}
\hline Isolate & VT & Date* & $\mathrm{I} / \mathrm{N}+$ & $s f b I$ & prtFII & $\mathrm{OF}$ & Site: & Isolate & VT & Date* & $\mathrm{I} / \mathrm{N} \dagger$ & $s f b I$ & prtFII & $\mathrm{OF}$ & Sitet \\
\hline NS 730 & $2 \cdot 2$ & $24 / 2 / 96$ & I & + & + & + & $\mathrm{N}$ & NS 282 & $17 \cdot 2$ & $5 / 3 / 95$ & $\mathrm{~N}$ & - & - & - & W \\
\hline NS 210 & 34 & $3 / 6 / 94$ & I & + & + & + & B & NS 836 & 46 & $12 / 5 / 96$ & $\mathrm{~N}$ & - & - & - & W \\
\hline NS 931 & 57 & $13 / 9 / 96$ & I & + & - & - & $\mathrm{N}$ & NS 1033 & $3 \cdot 22$ & $14 / 1 / 97$ & $\mathrm{~N}$ & + & - & - & W \\
\hline NS 192 & $3 \cdot 2$ & $12 / 4 / 94$ & I & + & + & + & $\mathrm{B}$ & NS $50 \cdot 1$ & $12 \cdot 1$ & $22 / 10 / 91$ & $\mathrm{~N}$ & - & - & - & W \\
\hline NS 13 & 24 & 19/2/91 & I & - & + & - & B & NS 179 & $7 \cdot 2$ & $22 / 3 / 94$ & $\mathrm{~N}$ & + & + & + & W \\
\hline NS 101 & $33 \cdot 1$ & $11 / 12 / 92$ & I & + & + & - & B & NS 53 & $29 \cdot 1$ & $6 / 11 / 91$ & $\mathrm{~N}$ & - & + & - & W \\
\hline NS 1140 & 101 & $27 / 4 / 97$ & I & - & + & - & B & NS 265 & 11 & $1 / 3 / 95$ & $\mathrm{~N}$ & - & + & - & W \\
\hline NS 235 & 118 & $14 / 11 / 94$ & I & - & + & - & B & NS 351 & 22 & $20 / 4 / 95$ & $\mathrm{~N}$ & + & - & + & W \\
\hline NS 1 & 23 & $16 / 7 / 90$ & I & - & + & - & B & NS 436 & $3 \cdot 3$ & $19 / 6 / 95$ & $\mathrm{~N}$ & - & + & + & W \\
\hline NS 178 & 26 & $21 / 3 / 94$ & I & - & + & - & B & NS 32 & $29 \cdot 2$ & $21 / 6 / 91$ & $\mathrm{~N}$ & - & - & - & W \\
\hline NS 43 & 9 & $15 / 8 / 91$ & I & - & - & + & B & NS 1096 & 32 & $24 / 3 / 97$ & $\mathrm{~N}$ & - & - & + & W \\
\hline NS $88 \cdot 2$ & $17 \cdot 4$ & $29 / 7 / 92$ & I & - & - & - & B & NS 506 & 134 & $22 / 8 / 95$ & $\mathrm{~N}$ & + & + & - & W \\
\hline NS 125 & $20 \cdot 1$ & $29 / 6 / 93$ & I & - & + & - & B & NS 1045 & 117 & $21 / 1 / 97$ & $\mathrm{~N}$ & + & - & + & W \\
\hline NS 240 & 116 & $30 / 1 / 95$ & I & + & + & + & B & NS 564 & 119 & $2 / 10 / 95$ & $\mathrm{~N}$ & + & + & - & $\mathrm{W}$ \\
\hline NS 225 & 115 & $13 / 10 / 94$ & I & - & + & - & B & NS 581 & 42 & $13 / 10 / 95$ & $\mathrm{~N}$ & - & + & - & W \\
\hline NS 90 & 52 & $19 / 8 / 92$ & I & + & + & - & B & NS 611 & $3 \cdot 7$ & $19 / 11 / 95$ & $\mathrm{~N}$ & + & - & - & $\mathrm{W}$ \\
\hline NS 223 & 4 & $30 / 9 / 94$ & I & - & + & - & B & NS 671 & 133 & $18 / 12 / 95$ & $\mathrm{~N}$ & - & + & + & W \\
\hline NS 1133 & $17 \cdot 1$ & $29 / 4 / 97$ & I & - & + & + & B & NS 684 & 132 & $2 / 1 / 96$ & $\mathrm{~N}$ & + & + & + & W \\
\hline NS 83 & $37 \cdot 1$ & 29/6/92 & I & + & + & + & B & NS 803 & 131 & $13 / 4 / 96$ & $\mathrm{~N}$ & - & + & - & W \\
\hline NS 50 & 5 & $17 / 10 / 91$ & I & - & + & - & B & NS 804 & 130 & $15 / 4 / 96$ & $\mathrm{~N}$ & + & - & - & W \\
\hline NS 226 & $14 \cdot 1$ & $13 / 10 / 94$ & I & + & + & - & $\mathrm{B}$ & NS 980 & 129 & $12 / 11 / 96$ & $\mathrm{~N}$ & + & - & + & W \\
\hline NS 8 & 25 & $1 / 1 / 90$ & I & + & + & + & B & NS 1030 & 77 & $10 / 1 / 97$ & $\mathrm{~N}$ & + & + & - & W \\
\hline NS 80 & 69 & $23 / 6 / 92$ & I & - & + & - & B & NS 1095 & 128 & $25 / 3 / 97$ & $\mathrm{~N}$ & + & - & + & W \\
\hline NS 344 & 127 & $15 / 4 / 95$ & I & + & - & - & B & NS 1099 & 126 & $1 / 4 / 97$ & $\mathrm{~N}$ & - & + & - & W \\
\hline NS 476 & 39 & $17 / 7 / 95$ & I & - & + & - & B & NS 1122 & 65 & $22 / 4 / 97$ & $\mathrm{~N}$ & + & - & + & W \\
\hline NS 6 & $12 \cdot 2$ & $1 / 1 / 90$ & I & - & + & - & B & NS 1185 & 135 & $7 / 7 / 97$ & $\mathrm{~N}$ & - & - & - & W \\
\hline NS 20 & $3 \cdot 4$ & $7 / 5 / 91$ & I & + & - & + & B & NS 1210 & 125 & $17 / 8 / 97$ & $\mathrm{~N}$ & + & - & + & W \\
\hline NS 25 & 18 & $12 / 6 / 91$ & I & + & - & - & B & NS 1216 & $49 \cdot 1$ & $10 / 8 / 97$ & $\mathrm{~N}$ & + & - & + & W \\
\hline NS 66 & $41 \cdot 2$ & $17 / 3 / 92$ & I & + & - & + & $\mathrm{B}$ & NS 1353 & 44 & $7 / 1 / 98$ & $\mathrm{~N}$ & + & + & - & W \\
\hline NS 195 & 120 & $19 / 4 / 94$ & I & - & + & - & B & NS 180 & 110 & $22 / 3 / 94$ & $\mathrm{~N}$ & - & + & - & $\mathrm{T}$ \\
\hline NS 78 & 30 & $23 / 6 / 92$ & I & + & - & + & B & NS 182 & 60 & $24 / 3 / 94$ & $\mathrm{~N}$ & - & + & + & $\mathrm{T}$ \\
\hline NS 204 & 121 & $18 / 5 / 94$ & I & + & - & + & B & NS 199 & 55 & $5 / 5 / 94$ & $\mathrm{~N}$ & + & + & + & $\mathrm{T}$ \\
\hline NS 205 & $20 \cdot 2$ & $23 / 5 / 94$ & I & - & + & - & B & NS 236 & 111 & $16 / 11 / 94$ & $\mathrm{~N}$ & - & + & + & $\mathrm{T}$ \\
\hline NS 216 & 122 & $14 / 6 / 94$ & I & - & - & - & B & NS 672 & 112 & $19 / 12 / 95$ & $\mathrm{~N}$ & + & + & + & $\mathrm{T}$ \\
\hline NS 878 & 124 & 1/6/96 & I & + & + & + & B & NS 678 & 113 & $23 / 12 / 95$ & $\mathrm{~N}$ & + & - & + & $\mathrm{T}$ \\
\hline NS 909 & 123 & $20 / 8 / 96$ & I & + & + & + & $\mathrm{B}$ & NS 696 & 114 & $16 / 1 / 96$ & $\mathrm{~N}$ & - & - & - & $\mathrm{T}$ \\
\hline NS 567 & 38 & $10 / 10 / 95$ & I & + & - & - & B & NS 1107 & $33 \cdot 3$ & $2 / 4 / 97$ & $\mathrm{~N}$ & + & - & + & $\mathrm{T}$ \\
\hline NS 14 & 96 & $26 / 1 / 91$ & $\mathrm{~N}$ & + & + & + & W & & & & & & & & \\
\hline
\end{tabular}

* Collection date of isolates.

$\dagger \mathrm{I}$ and $\mathrm{N}$ refer to classification of isolates from invasive and non-invasive cases respectively.

$\$$ Site or disease from which the organism was isolated: $\mathrm{N}$, necrotizing fasciitis; $\mathrm{B}$, bacteraemia; $\mathrm{W}$, wound skin; $\mathrm{T}$, throat.

labelled probes to screen for $s f b I$ and prtFII as described earlier [19]. A similar approach to screen for $s f b I I$ often gave ambiguous results as the hybridization signals were weak, possibly due to sequence variation in $s f b I I$. Therefore, for this study the $s f b I I$ status was inferred using opacity factor assays, which correlates well with the genotype; in our earlier study, 24 of $25 s f b I I$ positive strains are OF-positive [19]. Assay for opacity factor: This assay was performed as described previously [23]. Briefly, overnight cultures $(5 \mathrm{ml})$ in Todd Hewitt broth containing $2 \%$ neopep- tone were centrifuged and $10 \mu \mathrm{l}$ of the supernatant mixed with $100 \mu 1$ horse serum in microtitre plate wells. The plates were then incubated at $37^{\circ} \mathrm{C}$ overnight in a humid chamber. One hundred microlitres of saline was mixed with the contents of each well and then each well scored for opalescence.

Screening for fbp54 by PCR: Specific primers (5'CCGGATCCATGATTATGCGTAAATACCTCCAG-3' and 5'-CCCTGCAGTGCTTATCAGAATAATTTCATAGAGAGAATTTTGGC-3') were used 
(underlined sequence contained restriction sites not present in the $f b p 54$ gene). PCR conditions employed were as described above with an initial cycle of $94{ }^{\circ} \mathrm{C}$ for $2 \mathrm{~min}, 57^{\circ} \mathrm{C}$ for $2 \mathrm{~min}$ and $72{ }^{\circ} \mathrm{C}$ for $2 \mathrm{~min}$. Amplification consisted for 35 cycles at $94{ }^{\circ} \mathrm{C}$ for $1 \mathrm{~min}, 57^{\circ} \mathrm{C}$ for $1 \mathrm{~min}$ and $72^{\circ} \mathrm{C}$ for $1.5 \mathrm{~min}$. The reaction was completed with a final cycle of $94^{\circ} \mathrm{C}$ for $1 \mathrm{~min}, 57^{\circ} \mathrm{C}$ for $1 \mathrm{~min}$ and $72^{\circ} \mathrm{C}$ for $7 \mathrm{~min}$.

\section{RESULTS AND DISCUSSION}

Our previous work showed that many commonly circulating group A streptococcal strain in the Northern Territory could cause invasive disease and there is no one dominant strain [4]. Given this observation, the demarcation between strains associated with invasive and uncomplicated infections is less defined. Nevertheless, it is possible that some strains have greater predilection for invasion. Specific virulence determinants that are required by strains to cause invasive diseases are unknown. Given that group A streptococcus may contain up to four genes encoding FBP's ( $f f b I, s f b I I$, prtFII and $f b p 54$ ) and that SfbI has been shown to be preferentially associated with persistent cases of infection in one study [16], the carriage of FBP genes by group A streptococcus isolates from non-invasive and invasive diseases was determined.

Since these $S$. pyogenes isolates belong to distinct vir types, they are epidemiologically unrelated isolates. Thirty-seven and 38 distinct vir types represented isolates from invasive and the uncomplicated infections respectively. Overall they comprise about two thirds of reported strains circulating in this region. All isolates were positive for $f b p 54$ without exception. For OF, $38 \%$ of strains from invasive and $50 \%$ strains from uncomplicated infections were positive $(P=$ $0 \cdot 288$ ) suggesting that this protein may not have a role in promoting invasive diseases. Since SfbI is sufficient for GAS invasion of host cells, we anticipated that a greater proportion of strains representing isolates from invasive diseases might be positive for this gene than those from uncomplicated infection. Contrary to this expectation, we did not find a difference in the distribution of $s f b I$ between the two sets of strains ( $P$ $=0.7342)$. This result suggests that SfbI-mediated internalization of host cells is not likely to be a necessary characteristic of group A streptococcus for invasive diseases. This interpretation is consistent with the lack of $s f b I$ among $M$ types 1 and 18 that are known to be associated with severe invasive diseases elsewhere [24].

There are a few minor disconcordant observations between this study and our earlier report [19]. Firstly, unlike in the previous study, we found a few (7 strains) OF-positive strains that are sfbI-negative. Nonetheless, a majority of OF-positive strains are sfbI-positive (26 strains). Secondly, of the 32 vir types common to both the studies, 7 strains showed different distributions for sfbI and sfbII/OF. Reasons for this could be due to different isolates representing the same vir types used in these studies. Despite these minor differences, there is overall agreement in the $s f b I$ and OF distribution in both the studies.

Forty-five of the $75 \mathrm{NT}$ strains $(60 \%)$ possess prtFII. A larger proportion $(70 \%)$ is represented among the strains from the blood than among the strains from uncomplicated infections $(50 \%)(P=$ $0 \cdot 073$ ). Although this is not statistically significant, the trend is important given high endemicity of group A streptococcus infection in this area ('passenger' strain hypothesis, see below).

S. pyogenes may utilize different adhesins for attachment and colonization of different tissues and for invasion. For instance, $M$ protein may mediate adherence to keratinocytes in the epidermis, whereas SfbI may be necessary for adherence of group A streptococcus to pharyngeal cells and Langerhans' cells, a component of the basal layer of the epidermis [25]. Different repertoires of adhesins and their regulators, and the interactions of the adhesins with each other may determine tissue tropism and pathogenicity of $S$.pyogenes. In Table 1, $21 \%$ of the strains from uncomplicated infections are from the throat. Comparison of the distribution of the FBP genes between these throat isolates and the wound/skin isolates revealed no significant difference $(P=1.000$ for $s f b I ; P=0.232$ for OF; $P=0.698$ for prtFII). Calculations on the permutations of association of OF, $s f b I$ and prtFII were also investigated but did not reveal any significant result. These observations suggest that the primary site of infection cannot be attributed to any of the four FBPs.

Several reports describe that a limited number of clones are responsible for group A streptococcal invasive diseases [26-29]. These studies were carried out in non-endemic regions for streptococcal infection where the per capita diversity of the organism is likely to be low. Our recent studies with isolates from the tropical NT where the per capita diversity of group A streptococcus is high [2] reveal that many strains may 
cause invasive disease and that there is no clonal spread of a dominant strain among both Aboriginal and non-Aboriginal residents. This raises questions regarding the identity of common features of the group A streptococcal strains, which render them more invasive. While prtFII is present in a greater proportion of invasive vir types, $30 \%$ of the vir types that were isolated from the invasive disease patients did not harbour the gene. This suggests that factors other than PrtFII, such as NAD glycohydrolase [30], may also increase the invasive propensity of group A streptococcus. Alternatively, in a population with a high pathogen load where infection with multiple types is common and where multiple types have been recovered from an impetigo lesion [31], a co-infecting prtFII-positive strain might somehow promote a less benign prtFII-negative 'passenger' strain to cause invasive disease.

Our finding, that the strains with genetic endowment of prtFII are more likely to be recovered from invasive disease cases than strains that lack the gene, has implications for an FBP-based vaccine. The knowledge of distribution of FBP genes among $S$. pyogenes isolates from defined geographical areas may provide a basis for selection of appropriate antigens. Finally, despite inference of an association between SfbI-mediated cellular uptake and persistent infection, our data failed to show greater distribution of $s f b I$ among strains from invasive disease cases.

\section{ACKNOWLEDGEMENTS}

The authors wish to acknowledge the grant support from the National Health and Medical Research.

\section{REFERENCES}

1. Martin DR, Sriprakash KS. Epidemiology of group A streptococcal disease in Australia and New Zealand. Australian Society for Microbiologists: Recent Adv Microbiol 1996; 4: 1-40.

2. Gardiner D, Hartas J, Hibble M, Goodfellow A, Currie B, Sriprakash KS. Molecular epidemiology of group A streptococcal infection in the Northern Territory of Australia. Adv Exp Med Biol 1997; 418: 317-21.

3. Carapetis JR, Wolff DR, Currie BJ. Acute rheumatic fever and rheumatic heart disease in the top end of Australia's Northern Territory. Med J Aust 1996; 164: 146-9.

4. Carapetis JR, Walker AM, Hibble M, Sriprakash KS, Currie BJ. Clinical and epidemiological features of group A streptococcal bacteraemia in a region with hyperendemic superficial streptococcal infection. Epidemiol Infect 1999; 122: 59-65.

5. Currie BJ, Carapetis JR. Skin infections and infestations in Aboriginal communities in northern Australia. Australas J Dermatol 2000; 41 : 139-43.

6. Wizemann TM, Adamou JE, Langermann S. Adhesins as targets for vaccine development. Emerg Infect Dis 1999; 5: 395-403.

7. Courtney HS, Dale JB, Hasty DI. Differential effects of the streptococcal fibronectin-binding protein, FBP54, on adhesion of group A streptococci to human buccal cells and HEp-2 tissue culture cells. Infect Immun 1996; 64: $2415-9$.

8. Courtney HS, Hasty DL, Li Y, Chiang HC, Thacker JL, Dale JB. Serum opacity factor is a major fibronectin-binding protein and a virulence determinant of M type 2 Streptococcus pyogenes. Mol Microbiol 1999; 32: 89-98.

9. Hanski E, Horwitz PA, Caparon MG. Expression of protein $\mathrm{F}$, the fibronectin-binding protein of Streptococcus pyogenes JRS4, in heterologous streptococcal and enterococcal strains promotes their adherence to respiratory epithelial cells. Infect Immun 1992; 60: 5119-25.

10. Jaffe J, Natanson-Yaron S, Caparon MG, Hanski E. Protein F2, a novel fibronectin-binding protein from Streptococcus pyogenes, possesses two binding domains. Mol Microbiol 1996; 21: 373-84.

11. Rocha CL, Fischetti VA. Identification and characterization of a novel fibronectin-binding protein on the surface of group A streptococci. Infect Immun 1999; 67: $2720-8$.

12. Talay SR, Valentin-Weigand P, Jerlstrom PG, Timmis KN, Chhatwal GS. Fibronectin-binding protein of Streptococcus pyogenes: sequence of the binding domain involved in adherence of streptococci to epithelial cells. Infect Immun 1992; 60: 3837-44.

13. Molinari G, Talay SR, Valentin-Weigand P, Rohde M, Chhatwal GS. The fibronectin-binding protein of Streptococcus pyogenes, SfbI, is involved in the internalization of group A streptococci by epithelial cells. Infect Immun 1997; 65: 1357-63.

14. Kreikemeyer B, Talay SR, Chhatwal GS. Characterization of a novel fibronectin-binding surface protein in group A streptococci. Mol Microbiol 1995; 17: 137-45.

15. Kreikemeyer B, Martin DR, Chhatwal GS. SfbII protein, a fibronectin binding surface protein of group A streptococci, is a serum opacity factor with high serotype-specific apolipoproteinase activity. FEMS Microbiol Lett 1995; 178: 305-11.

16. Neeman R, Keller N, Barzilai A, Korenman Z, Sela S. Prevalence of internalization-associated gene, prtF1, among persisting group-A streptococcus strains isolated from asymptomatic carriers. Lancet 1998; 352: 1974-7.

17. Sela S, Neeman R, Keller N, Barzilai A. Relationship between asymptomatic carriage of Streptococcus pyogenes and the ability of the strains to adhere to and be internalized by cultured epithelial cells. J Med Microbiol 2000; 49: 499-502. 
18. Brandt CM, Allerberger F, Spellerberg B, Holland R, Lutticken R, Haase G. Characterization of consecutive Streptococcus pyogenes isolates from patients with pharyngitis and bacteriological treatment failure: special reference to prtF1 and sic/drs. J Infect Dis 2001; 183: $670-4$

19. Goodfellow AM, Hibble M, Talay SR, et al. Distribution and antigenicity of fibronectin binding proteins (SfbI and SfbII) of Streptococcus pyogenes clinical isolates from the northern territory, Australia. J Clin Microbiol 2000; 38: 389-92.

20. Fiorentino TR, Beall B, Mshar P, Bessen DE. A genetic-based evaluation of the principal tissue reservoir for group A streptococci isolated from normally sterile sites. J Infect Dis 1997; 176: 177-82.

21. Hartas J, Hibble M, Sriprakash KS. Simplification of a locus-specific DNA typing method (Vir typing) for Streptococcus pyogenes. J Clin Microbiol 1998; 36: 1428-9.

22. Chassy BM. A gentle method for the lysis of oral streptococci. Biochem Biophys Res Commun 1976; 68: 603-8.

23. Johnson DR, Kaplan EL. Microtechnique for serum opacity factor characterization of group A streptococci adaptable to the use of human sera. J Clin Microbiol 1988; 26: 2025-30.

24. Podbielski A, Woischnik M, Leonard BA, Schmidt $\mathrm{KH}$. Characterization of nra, a global negative regulator gene in group A streptococci. Mol Microbiol 1999; 31: 1051-64.
25. Okada N, Pentland AP, Falk P, Caparon MG. M protein and protein $\mathrm{F}$ act as important determinants of cell-specific tropism of Streptococcus pyogenes in skin tissue. J Clin Invest 1994; 94: 965-77.

26. Chaussee MS, Liu J, Stevens DL, Ferretti JJ. Genetic and phenotypic diversity among isolates of Streptococcus pyogenes from invasive infections. $\mathbf{J}$ infect Dis 1996; 173: 901-8.

27. Musser JM, Hauser AR, Kim MH, Schlievert PM, Nelson K, Selander RK. Streptococcus pyogenes causing toxic-shock-like syndrome and other invasive diseases: clonal diversity and pyrogenic exotoxin expression. Proc Natl Acad Sci USA 1991; 88: 2668-72.

28. Upton M, Carter PE, Morgan M, Edwards GF, Pennington TH. Clonal structure of invasive Streptococcus pyogenes in Northern Scotland. Epidemiol Infect 1995; 115: 231-41.

29. Wolf JE, Rabinowitz LG. Streptococcal toxic shocklike syndrome. Arch Dermatol 1995; 131: 73-7.

30. Stevens DL, Salmi DB, Mclndoo ER, Bryant AE. Molecular epidemiology of $n g a$ and NAD glycohydrolase/ADP-ribosyltransferase activity among Streptococcus pyogenes causing streptococcal toxic shock syndrome. J Infect Dis 2000; 182: 1117-28.

31. Carapetis J, Gardiner D, Currie B, Mathews JD. Multiple strains of Streptococcus pyogenes in skin sores of aboriginal Australians. J Clin Microbiol 1995; 33: $1471-2$. 